\title{
Porous Diatomite-Immobilized Cu-Ni Bimetallic Nanocatalysts for Direct Synthesis of Dimethyl Carbonate
}

\author{
Yong Chen, ${ }^{1}$ Min Xiao, ${ }^{1}$ Shuanjin Wang, ${ }^{1}$ Dongmei Han, ${ }^{1}$ Yixin $L u,{ }^{2}$ and Yuezhong Meng ${ }^{1}$ \\ ${ }^{1}$ State Key Laboratory of Optoelectronic Materials and Technologies and The Key Laboratory of Low-Carbon Chemistry \& Energy \\ Conservation of Guangdong Province, Sun Yat-Sen University, Guangzhou 510275, China \\ ${ }^{2}$ Department of Chemistry and Medicinal Chemistry Program, Office of Life Sciences, National University of Singapore, \\ 3 Science Drive 3, Singapore 117543 \\ Correspondence should be addressed to Shuanjin Wang, wangshj@mail.sysu.edu.cn and \\ Yuezhong Meng, mengyzh@mail.sysu.edu.cn
}

Received 23 March 2011; Revised 18 July 2011; Accepted 17 August 2011

Academic Editor: Mohammad Reza Bayati

Copyright (C) 2012 Yong Chen et al. This is an open access article distributed under the Creative Commons Attribution License, which permits unrestricted use, distribution, and reproduction in any medium, provided the original work is properly cited.

\begin{abstract}
A series of diatomite-immobilized $\mathrm{Cu}-\mathrm{Ni}$ bimetallic nanocatalysts was prepared under ultrasonication and evaluated for the direct synthesis of dimethyl carbonate under various conditions. Upon being fully characterized by TPR, TPD, BET, SEM, XRD, and XPS methodologies, it is found that the bimetallic composite is effectively alloyed and well immobilized inside or outside the pore of diatomite. Under the optimal conditions of $1.2 \mathrm{MPa}$ and $120^{\circ} \mathrm{C}$, the prepared catalyst with loading of $15 \%$ exhibited the highest methanol conversion of $6.50 \%$ with DMC selectivity of $91.2 \%$ as well as more than 10 -hour lifetime. The possible reaction mechanism was proposed and discussed in detail. To our knowledge, this is the first report to use diatomite as a catalyst support for direct DMC synthesis from methanol and $\mathrm{CO}_{2}$.
\end{abstract}

\section{Introduction}

Dimethyl carbonate (DMC), an environment-friendly chemical, has attracted much attention as methylating and carbonylating agents, fuel additives, as well as polar solvents [1-4]. Several commercial processes have been introduced for synthesis of DMC, including methanolysis of phosgene [5], ester exchange process $[6,7]$, methanolysis of urea [8], and gas-phase oxidative carbonylation of methanol [9]. However, all these processes use toxic, corrosive, flammable, and explosive gases such as phosgene, hydrogen chloride, and carbon monoxide. Therefore, direct synthesis of DMC from $\mathrm{CH}_{3} \mathrm{OH}$ and $\mathrm{CO}_{2}$ is highly desired since such an approach is environment friendly by nature [1].

Carbon dioxide, the main greenhouse gas, can be converted into synthetic gas, methanol, acetic acid, carbonate, and so forth, [10]. However, it is still a big challenge for synthetic chemists to utilize $\mathrm{CO}_{2}$ effectively due to its in-built thermodynamic stability and kinetic inertness. Recently, a large number of catalysts have been reported for the direct synthesis of DMC from $\mathrm{CO}_{2}$ and $\mathrm{CH}_{3} \mathrm{OH}$ including organometallic compounds [11], potassium methoxide [12], $\mathrm{ZrO}_{2}, \mathrm{Ce}_{0.5} \mathrm{Zr}_{0.5} \mathrm{O}_{2}$ and $\mathrm{H}_{3} \mathrm{PW}_{12} \mathrm{O}_{4}-\mathrm{Ce}_{x} \mathrm{Ti}_{1-x} \mathrm{O}_{2}$, [13-15], $\mathrm{H}_{3} \mathrm{PO}_{4}-\mathrm{V}_{2} \mathrm{O}_{5}$ catalyst [16], and so forth. However, the highest DMC yield was still very low without addition of strong base and dehydrating agent due to the difficulties in activation of $\mathrm{CO}_{2}$ and the deactivation of catalysts by in situ produced water. Copper and nickel composite, a type of novel bimetallic catalyst, was firstly proved highly active for direct synthesis of DMC by the Zhong Group [17]. In our group, Wu et al. further optimized the preparation condition and catalytic process of the catalysts [18]. For enhancing the efficiency of $\mathrm{Cu}-\mathrm{Ni}$ catalysts, Wang et al. tested the similar $\mathrm{Cu}-(\mathrm{Ni}, \mathrm{V}, \mathrm{O}) / \mathrm{SiO}_{2}$ catalyst with UV irradiation and pushed DMC yield close to $5 \%[19,20]$. Recently Bian et al. pioneered to support $\mathrm{Cu}-\mathrm{Ni}$ composite on conductive carbon materials and firstly improved the methanol conversion to $10.13 \%$ with DMC selectivity of $90.2 \%[21,22]$. The catalysts above mentioned offer different advantages over others before them but also have considerable shortcomings 
such as complicated preparation process, expensive support, and bleak prospect for industrialization. Therefore, new catalysts with low cost, high catalytic performance, and simple preparation process are urgently required.

Diatomite, a type of widespread natural porous material, has been widely used as filler aid, adsorbent, and catalytic support in the reaction such as hydrogenation [23], oxidation [24], Fischer-Tropsch synthesis [25], $\mathrm{CO}_{2}$ reduction [26] and so forth due to its unique high-adsorption capacity, high surface area, and cheap availability. In this connection, a series of $\mathrm{Cu}-\mathrm{Ni} /$ diatomite bimetallic catalysts were prepared and evaluated under variable reaction conditions in this work.

\section{Experimental}

2.1. Catalyst Preparation. Natural diatomite was pretreated by calcining at $500^{\circ} \mathrm{C}$ for $3 \mathrm{~h}$, soaking in $5 \%$ hydrochloric acid for $24 \mathrm{~h}$, and washing and drying at $110^{\circ} \mathrm{C}$ overnight. $\mathrm{Cu}-\mathrm{Ni}$ /diatomite nanocatalyst was prepared by the wetness impregnation method. Firstly $\mathrm{Cu}\left(\mathrm{NO}_{3}\right)_{2} \cdot 3 \mathrm{H}_{2} \mathrm{O}(0.517 \mathrm{~g})$ and $\mathrm{Ni}\left(\mathrm{NO}_{3}\right)_{2} \cdot 6 \mathrm{H}_{2} \mathrm{O}(0.311 \mathrm{~g})$ were dissolved in $25 \mathrm{~mL}$ of $25 \mathrm{wt} \%$ ammonia solution by stirring, then $5 \mathrm{~g}$ of diatomite was dispersed in metallic ammonia solution. The resulting mixture was stirred at room temperature for $24 \mathrm{~h}$, ultrasonicated for another $3 \mathrm{~h}$, followed by rotavaporation to remove the solvent. Thereafter, it was dried at $110^{\circ} \mathrm{C}$ overnight. The fully dried solid was calcined at $500^{\circ} \mathrm{C}$ for $5 \mathrm{~h}$ and further reduced by $5 \% \mathrm{~h}_{2} / \mathrm{N}_{2}$ mixture at $550^{\circ} \mathrm{C}$ for $6 \mathrm{~h}$.

2.2. Catalyst Characterization. The surface area of the samples was detected in liquid $\mathrm{N}_{2}$ by the Brunauer-EmmettTeller (BET) approaches using a Micromeritics ASAP 2010 instrument. Thermogravimetric analyses (TGA) of samples were performed on a PerkinElmer Pyris Diamond SII thermal analyzer (high-purity $\mathrm{N}_{2}, 20^{\circ} \mathrm{C} / \mathrm{min}$ ). The morphologies of the samples were examined using a scanning electron microscopy (SEM) (JSM-5600LV system of JEOL) equipped with an energy dispersive X-ray spectrometer (EDX) to check the components of the catalysts. The phase structure of the samples were determined by X-ray diffraction (XRD) on a D/Max-IIIA power diffractometer using $\mathrm{Cu}$ $(\mathrm{K} \alpha)(0.15406 \mathrm{~nm})$ radiation source. X-ray photoelectron spectrum (XPS) of the catalysts was obtained by ESCALAB 250 (Thermo-VG Scientific) analyzer using the monochromatized $\mathrm{Al}(\mathrm{K} \alpha)$ radiation source. Temperature-programmed reduction (TPR)/temperature-programmed desorption of ammonia $\left(\mathrm{NH}_{3}\right.$-TPD) experiments of the samples were detected by Quantachrome ChemBET 3000 apparatus equipped with a thermal conductivity detector (TCD) [22].

The evaluation of the catalysts was performed in a continuous tubular fixed-bed microgaseous reactor with $2 \mathrm{~g}$ of the fresh catalyst and $2 / 1$ molar ratio of $\mathrm{CH}_{3} \mathrm{OH} / \mathrm{CO}_{2}$ ( $30 \mathrm{~mL} / \mathrm{min}$ flux). It was carried out at different temperatures and different pressures. The product was analyzed by on-line GC (GC7890F) equipped with a flame ionization detector

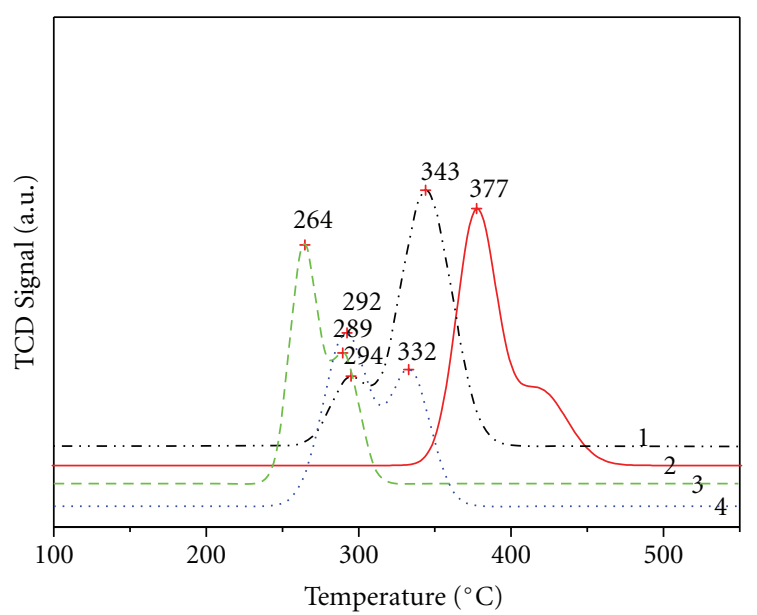

(1) $15 \% \mathrm{CuO} /$ diatomite

(2) $15 \% \mathrm{NiO} /$ diatomite

(3) $15 \%(2 \mathrm{CuO}-\mathrm{NiO})$

(4) $15 \%(2 \mathrm{CuO}-\mathrm{NiO}) /$ diatomite

FIgURE 1: TPR test of the samples.

and GCMS-QP2010 Plus. The final results were calculated by the following equations:

$$
\begin{aligned}
\mathrm{CH}_{3} \mathrm{OH} \text { conversion }(\%)= & \frac{\left[\mathrm{CH}_{3} \mathrm{OH} \text { reacted }\right]}{\left[\mathrm{CH}_{3} \mathrm{OH} \text { total }\right]} \times 100 \%, \\
\text { DMC selectivity }(\%)= & \frac{[\mathrm{DMC}]}{[\mathrm{DMC}+\text { Byproduct }]} \times 100 \%, \\
\text { DMC yield }(\%)= & \mathrm{CH}_{3} \mathrm{OH} \text { conversion } \\
& \times \text { DMC selectivity } \times 100 \% .
\end{aligned}
$$

\section{Results and Discussion}

3.1. Structural Investigation of the Catalysts. Natural diatomite was simply pretreated to further enlarge the surface area. Intensive stirring and more than $3 \mathrm{~h}$ strong ultrasonication were pretty favorable for impregnation of bimetallic solution. TPR of the samples was shown in Figure 1. The supported bimetallic catalyst shows two closely overlapped reduction peaks, one was the reduction of $\mathrm{CuO}\left(292^{\circ} \mathrm{C}\right)$ and the other was the reduction of $\mathrm{NiO}\left(332^{\circ} \mathrm{C}\right)$. Moreover, the reduction temperature of supported bimetallic catalyst shifted to lower temperature than monometallic catalyst, indicating the tremendous contribution of strong interaction of copper and nickel. In addition, the reduction temperature of supported bimetallic catalyst was higher than unsupported bimetallic composite $\left(\mathrm{CuO} 264^{\circ} \mathrm{C}, \mathrm{NiO} 289^{\circ} \mathrm{C}\right)$, attributing to the strong interaction of bimetallic composite with support.

Morphology of the samples was observed by SEM as presented in Figure 2. Diatomite was porous disc with some blocked pore before pretreatment (a). After pretreatment, it was disintegrated into fragment with allover straightway 


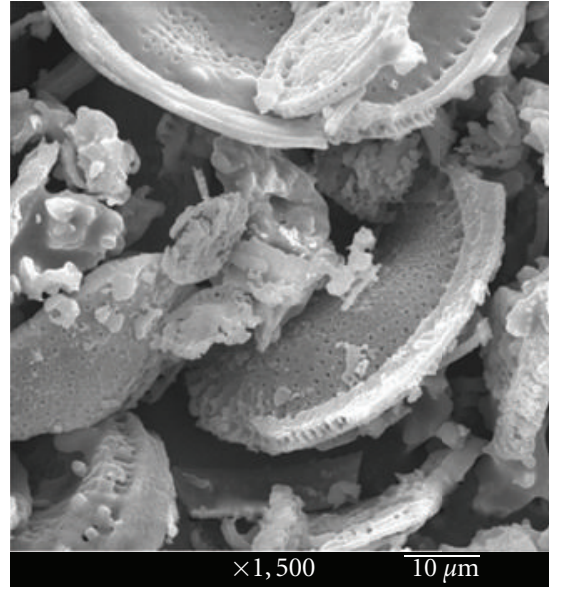

(a)

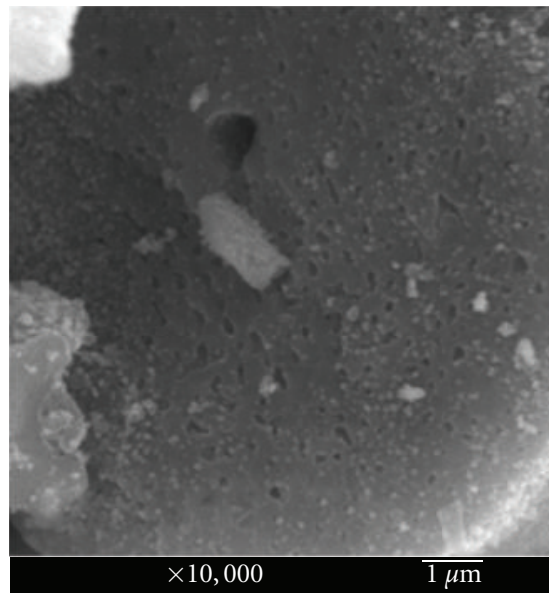

(c)

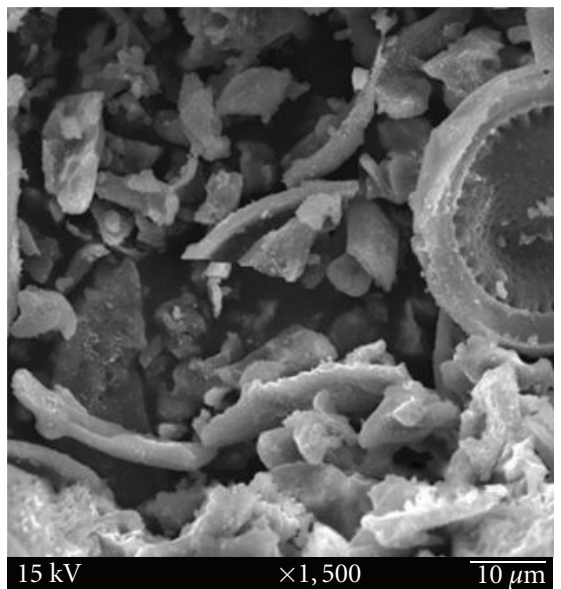

(b)

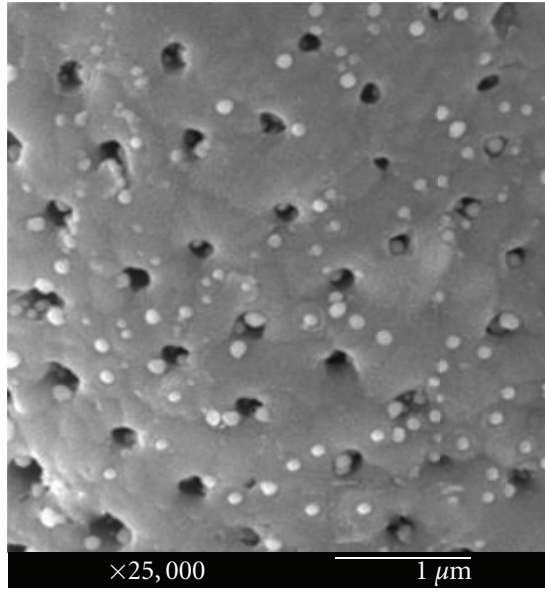

(d)

Figure 2: SEM of the samples. (a) Natural diatomite, (b) treated diatomite, (c) 15\% (2Cu-Ni)/diatomite $(\times 10000)$, and (d) $15 \%(2 \mathrm{Cu}-\mathrm{Ni}) /$ diatomite $(\times 25000)$.

pore (b), which was quite preferable for bimetallic dispersion and catalytic activity improvement. As shown in (c), diatomite was homogenously covered by bimetallic nanoparticles not only immobilizing on the surface, but also a great deal of them inlaying, the inner wall of the pore (d) which is quite preferred for bimetallic dispersion and stabilization.

Quantitative element analysis of the catalyst was performed by EDS (Figure SM1 which is available online at doi:10.1155/2012/610410). The average results of area analysis were $\mathrm{Cu} 8.12 \%$, Ni 3.86\%, Si 38.73\%, O 47.87\% with a little amount of $\mathrm{Fe}, \mathrm{Al}, \mathrm{Mn}$ which further confirmed that the bimetallic components were effectively loaded. Oxidative state of the element was determined by XPS (Figure 3). The survey scan spectra indicated bimetallic components of $\mathrm{Cu}$ and $\mathrm{Ni}$ was dispersed throughout the surface of the support besides a little ferric, manganic and aluminous oxides were also included in this system coming from diatomite which may be good active additives (c). Cu $2 p$ scan (a) and $\mathrm{Ni} 2 \mathrm{p}$ scan (b) displayed that binding energy of $\mathrm{Cu}$ and $\mathrm{Ni}$ was located at $932.73\left(\mathrm{Cu} 2 \mathrm{p}_{3 / 2}\right), 852.80\left(\mathrm{Ni} 2 \mathrm{p}_{3 / 2}\right)$,
$951.70\left(\mathrm{Cu} 2 \mathrm{p}_{1 / 2}\right), 858.60$ (Ni 2p $\mathrm{p}_{1 / 2}$ ), 918.70 (Cu LMM), and 846.20 (Ni LMM) respectively, which indicated that $\mathrm{Cu}-$ Ni composite was almost fully reduced. The XRD patterns of the samples were shown in Figure 4. Curve (a) was the typical patterns of diatomite with some weak diffractions of ferric oxide, alumina, and manganese dioxide. Compared with curve (a), curve (b) displayed new peaks of $\mathrm{CuO}$ and $\mathrm{NiO}$ accompanied by little diffraction of $\mathrm{Cu}_{2} \mathrm{O}$. Instead of diffraction of $\mathrm{CuO}$ and $\mathrm{NiO}$, these newly emerged peaks in curve (c) $(2 \theta=43.62,51.06,74.94$, and 91.04) were characteristic diffraction of $\mathrm{Cu}-\mathrm{Ni}$ alloy. Interestingly it was not two close diffraction peaks of $\mathrm{Cu}$ and $\mathrm{Ni}$ as depicted in [27] but a single peak of $\mathrm{Cu}-\mathrm{Ni}$ alloy, which may be due to the highly homogeneous distribution of $\mathrm{Cu}$ and $\mathrm{Ni}$ in $\mathrm{Cu}-\mathrm{Ni}$ nanoparticles resulting from the contribution of ultrasonic dispersion and support effect.

3.2. Adsorption Behavior of the Support and Catalyst. The specific surface area of the support and catalyst was conducted by the BET method. Natural and treated diatomite 


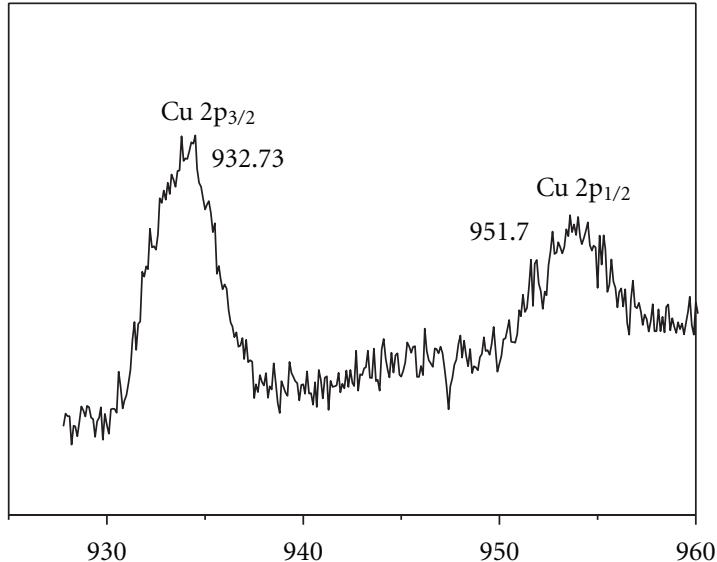

(a)

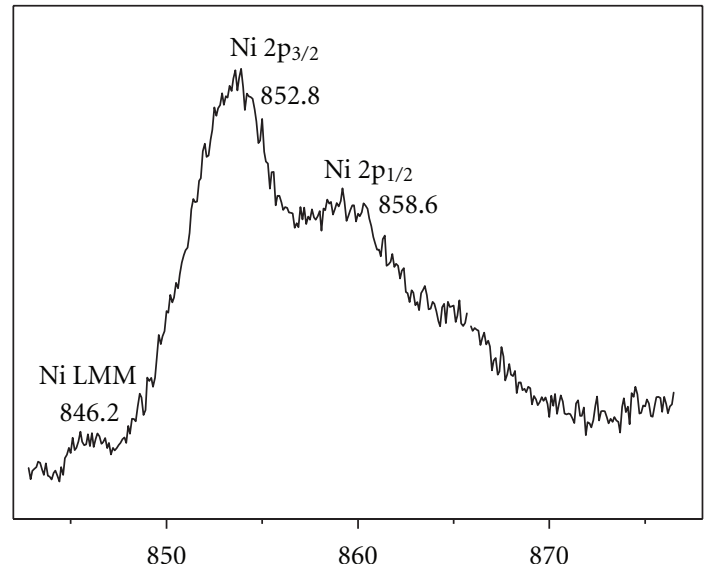

(b)

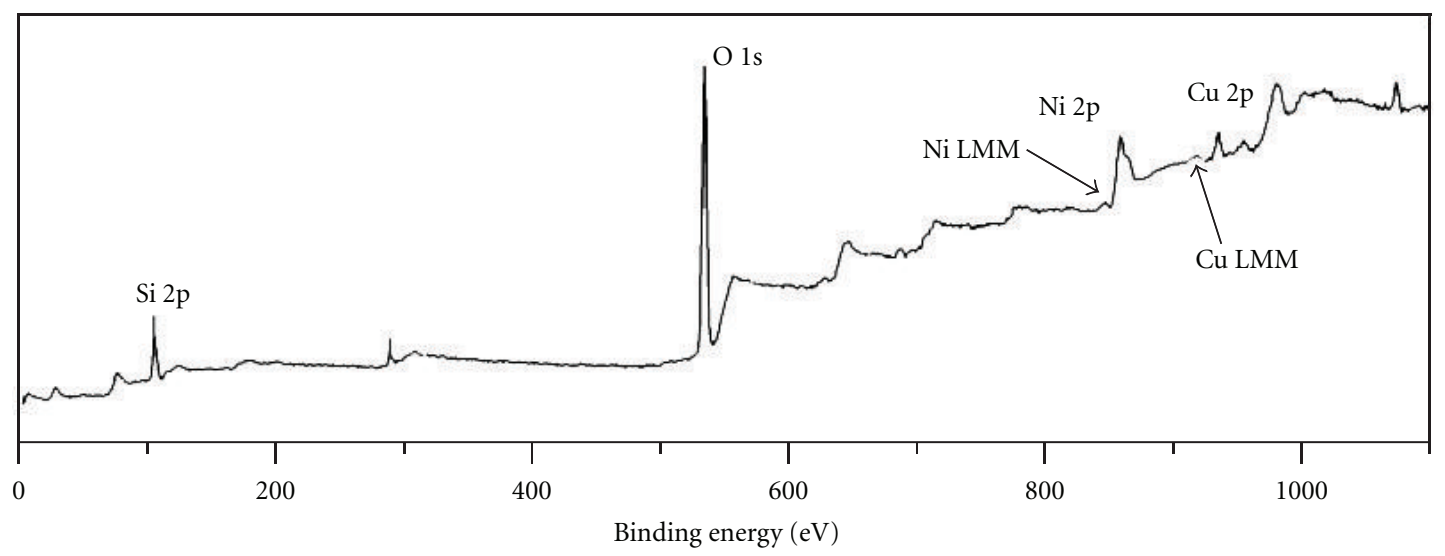

(c)

Figure 3: XPS of 15\% (2Cu-Ni)/diatomite catalyst. (a) Cu 2p scan, (b) Ni 2p scan, and (c) survey scan.

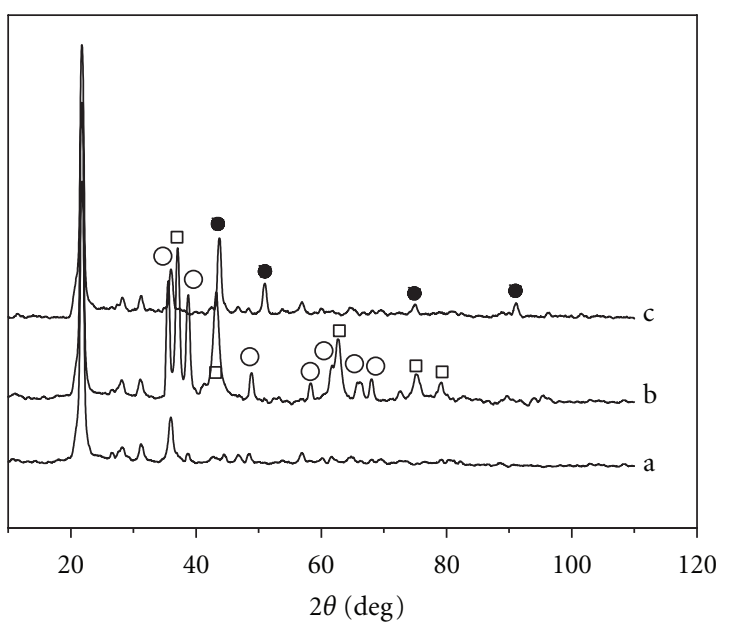
- : Cu-Ni alloy
$\mathrm{O}: \mathrm{CuO}$
(a) Diatomite
口: $\mathrm{NiO}$
(b) $15 \%(2 \mathrm{CuO}-\mathrm{NiO}) /$ diatomite
(c) $15 \%(2 \mathrm{Cu}-\mathrm{Ni}) /$ diatomite

FIGURE 4: XRD patterns of the samples. (a) treated diatomite, (b) $15 \%(2 \mathrm{CuO}-\mathrm{NiO}) /$ diatomite, and (c) $15 \%(2 \mathrm{Cu}-\mathrm{Ni}) /$ diatomite. were 58.36 and $77.57 \mathrm{~m}^{2} / \mathrm{g}$, respectively. $\mathrm{NH}_{3}$-TPD profiles of the samples were presented in Figure 5, it can be found that the desorption peak area of bimetallic catalyst was larger than those of monometallic catalyst, and all desorption was divided into three stages that were physical desorption, hydrogen-bonding desorption, acid-centered desorption around $130^{\circ} \mathrm{C}, 180^{\circ} \mathrm{C}$, and $270^{\circ} \mathrm{C}$, respectively. Physical desorption mainly results from surface sorption of the catalyst in order to reduce its surface free energy. In addition, bimetallic catalyst showed a little stronger physical desorption than monometallic catalyst. Hydrogen-bonding desorption comes from the strong interaction between free $\mathrm{Si}-\mathrm{OH}$ and $\mathrm{NH}_{3}$. Strong acid-centered desorption arises from the nude $\mathrm{M}^{+}$center $(\mathrm{M}=\mathrm{Si}, \mathrm{Cu}, \mathrm{Ni}, \mathrm{Al}$, etc. $)$, and the number of the acid center increases with increasing of ther desorption peak area. Meanwhile, the higher the temperature of the peak is, the stronger the acid center represents. It was worth noting that the acid strength increased with the order of $15 \%(2 \mathrm{Cu}-\mathrm{Ni}) /$ diatomite, $15 \% \mathrm{Cu} /$ diatomite, and $15 \% \mathrm{Ni} /$ diatomite, which was consistent with the order of their catalytic activity (see Table 1) and the acid-base catalysis mechanism $[13,28]$. 


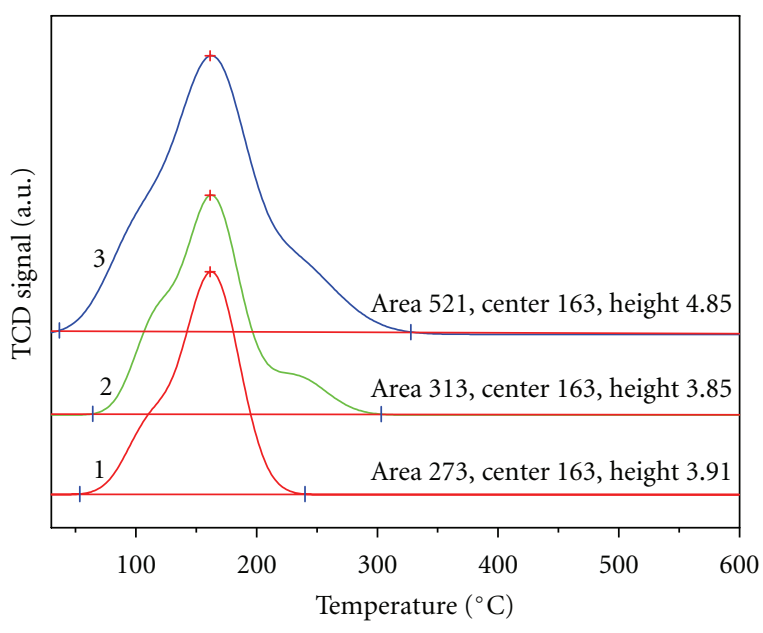

(1) $15 \% \mathrm{Ni} /$ diatomite

(2) $15 \% \mathrm{Cu} /$ diatomite

(3) $15 \%(2 \mathrm{Cu}-\mathrm{Ni}) /$ diatomite

Figure 5: $\mathrm{NH}_{3}-\mathrm{TPD}$ profiles of the catalysts.

3.3. Study on Performance of the Catalyst. The effect of loading on DMC synthesis was listed in Table 1 . The loading ranges from $3 \mathrm{wt} \%$ to $25 \mathrm{wt} \%$ with $2 / 1$ of $\mathrm{Cu} / \mathrm{Ni}$ [21], and the optimum loading was $15 \%$. The bimetallic catalysts were superior to monometallic catalysts which further verified the synergetic effect of the $\mathrm{Cu}-\mathrm{Ni}$ alloy [21].

The effect of pressure, temperature, and space velocity on highly active $15 \%(2 \mathrm{Cu}-\mathrm{Ni})$ /diatomite catalyst was evaluated as the most important factors (Figure 6). The $\mathrm{CH}_{3} \mathrm{OH}$ conversion, DMC yield, and selectivity were enhanced noticeably with pressure increase (6a). Nevertheless, it leveled off when pressure climbed over 1.2 $\mathrm{MPa}$, indicating much higher pressure would have less effect on the reaction. Under set conditions of $1.2 \mathrm{MPa}$ and $600 \mathrm{~h}^{-1}$, it gives the highest methanol conversion of $4.50 \%$ with DMC selectivity of $88.4 \%$ at $120^{\circ} \mathrm{C}(6 \mathrm{~b})$. Although increasing temperature was more favorable for activation of $\mathrm{CH}_{3} \mathrm{OH}$ and $\mathrm{CO}_{2}$, the catalytic performance decreased obviously over $120^{\circ} \mathrm{C}$ likely due to the $\mathrm{CO}_{2}$ and methanol desorption and the change of catalytic transition state. When the reaction was fixed at $120^{\circ} \mathrm{C}$ and $1.2 \mathrm{MPa}$, methanol conversion increased a little with increasing space velocity from 300 to $600 \mathrm{~h}^{-1}$ (6c), after that it collapsed gradually from 600 to $1500 \mathrm{~h}^{-1}$ because the reaction time correspondingly decreased with the increase of space velocity.

Stability test of the catalyst was conducted at $120^{\circ} \mathrm{C}$, 1.2 $\mathrm{MPa}$ and $600 \mathrm{~h}^{-1}$ (6d). The variation of $\mathrm{CH}_{3} \mathrm{OH}$ conversion and $\mathrm{DMC}$ selectivity with time was represented by stream on hour $(5 \mathrm{c})$. The $\mathrm{CH}_{3} \mathrm{OH}$ conversion climbs to the highest value of $4.57 \%$ within $2 \mathrm{~h}$ likely due to the initiation of active species in the initial reaction stage, finally it decreased slowly to $2.95 \%$. Simultaneously the DMC selectivity fluctuated from 92.0 to $88.6 \%$ probably resulting from the active center was poisoned by in situ produced water and surfcial oxidation of the catalyst. The byproducts were $\mathrm{CO}, \mathrm{HCHO}$, and dimethyl ether (DME) detected by

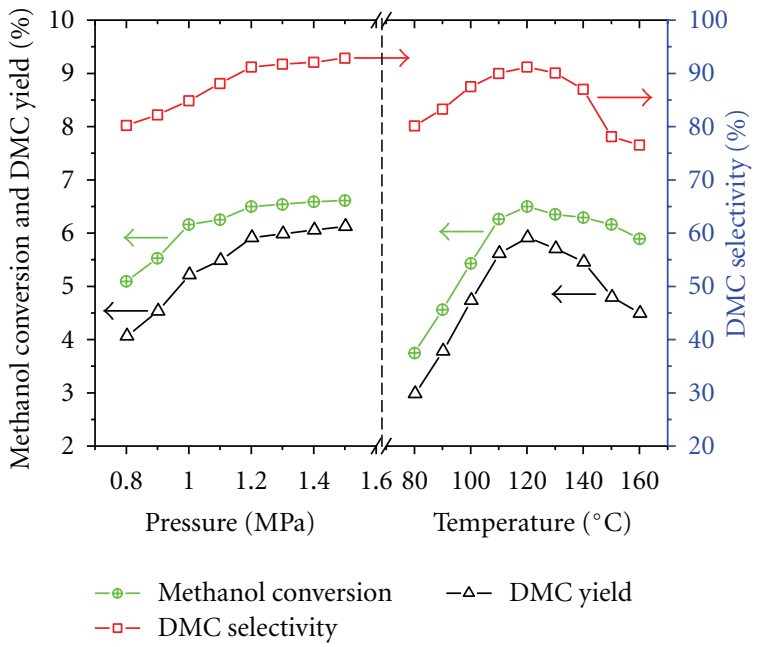

(a)

(b)

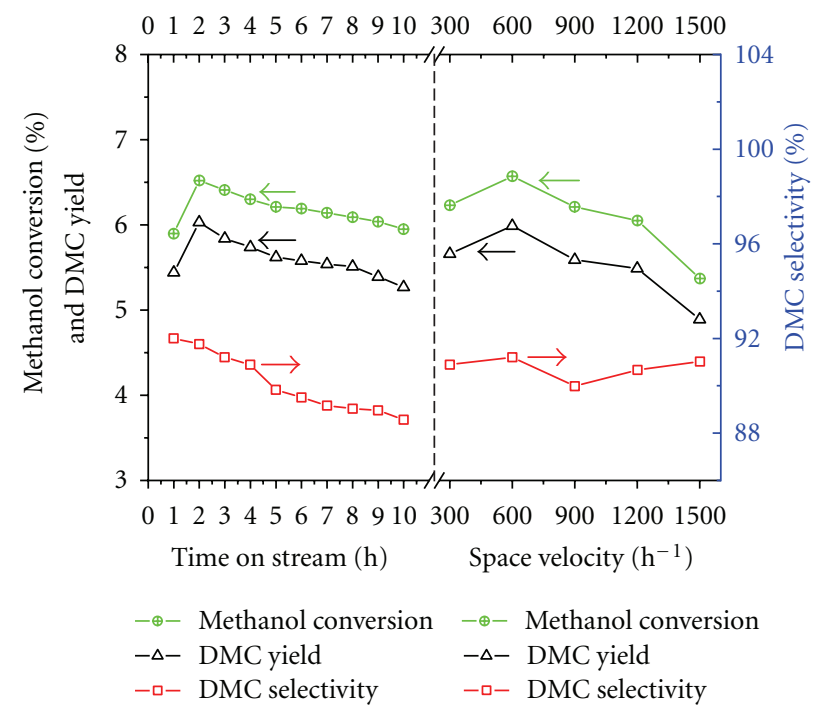

(d)

(c)

Figure 6: (a) Dependence of $15 \%(2 \mathrm{Cu}-\mathrm{Ni}) /$ diatomite performance on pressure $\left(120^{\circ} \mathrm{C}, 600 \mathrm{~h}^{-1} \mathrm{GHSV}\right)$. (b) Dependence of $15 \%$ (2Cu-Ni)/diatomite performance on temperature (1.2 MPa, $600 \mathrm{~h}^{-1}$ GHSV). (c) Dependence of $15 \%$ (2Cu-Ni)/diatomite performance on space velocity $\left(1.2 \mathrm{MPa}, 120^{\circ} \mathrm{C}\right)$. (d) Stability test of $15 \%(2 \mathrm{Cu}-\mathrm{Ni}) /$ diatomite $\left(120^{\circ} \mathrm{C}, 1.2 \mathrm{Mpa}, 600 \mathrm{~h}^{-1} \mathrm{GHSV}\right) .2 \mathrm{~g}$ catalyst and $n \mathrm{CH}_{3} \mathrm{OH} / n \mathrm{CO}_{2}=2 / 1$ were used for all tests.

GC-MS in this reaction. $\mathrm{CO}$ presumably came from the cleavage of $\mathrm{C}-\mathrm{O}$ bond of the activated $\mathrm{CO}_{2}$, whilst $\mathrm{HCHO}$ and DME may result from the activated $\mathrm{CH}_{3} \mathrm{OH}$.

\section{Proposed Reaction Mechanism}

In view of the above experimental results, a different reaction mechanism from the literatures $[21,22]$ was proposed based on the results of GC-MS and in situ FTIR. As shown in 


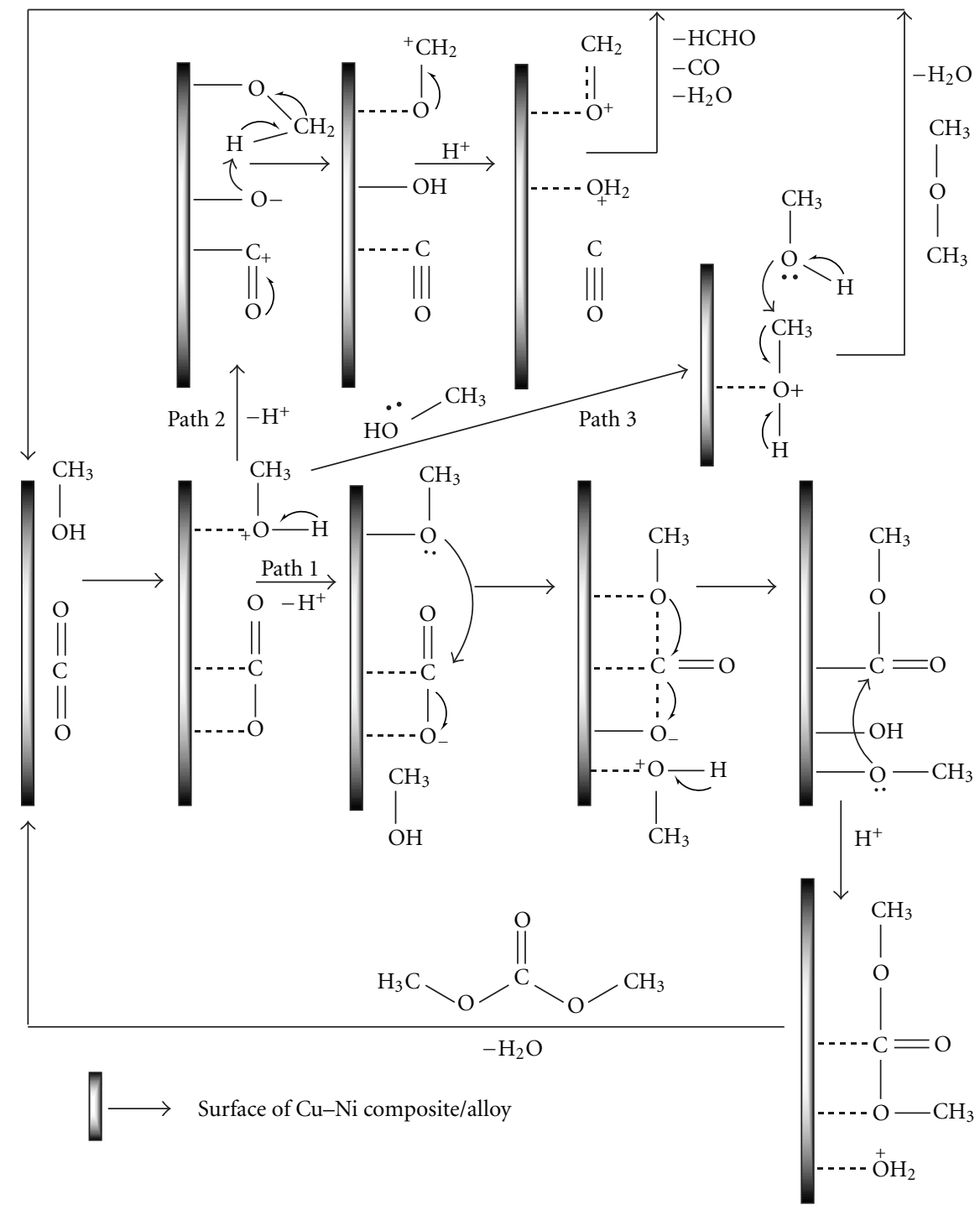

FIGURE 7: The proposed catalytic reaction mechanism for direct DMC synthesis from $\mathrm{CH}_{3} \mathrm{OH}$ and $\mathrm{CO}_{2}$ over $\mathrm{Cu}-\mathrm{Ni} /$ diatomite.

TABLE 1: Influence of bimetallic loading on the direct synthesis of DMC.

\begin{tabular}{lcccc}
\hline Entry & Loading $(\mathrm{wt} \%)^{\mathrm{a}}(2 \mathrm{CuO}+\mathrm{NiO})$ & Methanol conversion $^{\mathrm{b}}(\%)$ & DMC selectivity $(\%)$ & DMC yield $(\%)$ \\
\hline 1 & 3 & 2.32 & 89.4 & 90.2 \\
2 & 5 & 2.73 & 90.9 & 2.17 \\
3 & 10 & 3.96 & 91.2 & 2.42 \\
4 & 15 & 4.50 & 88.7 & 3.93 \\
5 & 20 & 4.05 & 86.1 & 2.36 \\
6 & 25 & 3.67 & 92.0 & 2.13 \\
$7^{\mathrm{c}}$ & 15 & 2.31 & 91.5 & 0.53 \\
$8^{\mathrm{d}}$ & 15 & 0.58 & & \\
\hline
\end{tabular}

${ }^{\mathrm{a}}$ Molar ratio of $\mathrm{CuO} / \mathrm{NiO}$ is $2 / 1$; ${ }^{\mathrm{b}}$ reaction conditions: $120^{\circ} \mathrm{C} ; 1.2 \mathrm{MPa}$; ${ }^{\mathrm{c}}$ only $\mathrm{Cu}$ was loaded; ${ }^{\mathrm{d}}$ only Ni was loaded.

Figure 7, a large number of basic $\left(\mathrm{M}^{-}\right)$and acid $\left(\mathrm{M}^{+}\right)$ centers existed on the surface of $\mathrm{Cu}-\mathrm{Ni}$ nanocomposite or the interface between $\mathrm{Cu}-\mathrm{Ni}$ and support, which were the residual bonds resulted from the synergetic interaction of $\mathrm{Cu}$ with $\mathrm{Ni}$ or $\mathrm{Cu}-\mathrm{Ni}$ with support. $\mathrm{CH}_{3} \mathrm{OH}$ and $\mathrm{CO}_{2}$ were firstly adsorbed on those $\mathrm{M}^{+}$and $\mathrm{M}^{-}$, respectively, simultaneously accompanied by methanol dehydrogenation and $\mathrm{CO}_{2}$ deoxygenation, which was the rate-determining step. DMC was formed by reaction path 1 ; $\mathrm{CO}$ and $\mathrm{HCHO}$ came out by path 2 ; DME was produced by dehydration 
of two methanol molecules through path $3 . \mathrm{M}^{+}$and $\mathrm{M}^{-}$ centers were regenerated and recycled by desorption of those produced molecules under heating. Otherwise those active centers were deactivated by $\mathrm{O}$ or $-\mathrm{OH}$ groups which were responsible for the loss of catalysis activity and the oxidization of $\mathrm{Cu}-\mathrm{Ni}$, so the existence of $\mathrm{H}_{2} \mathrm{O}$ may be lethal for this reaction. Although the real reaction path was not well understood and verified, this proposed reaction mechanism compared to the literatures $[21,22]$ will help us to better understand and explain the reaction results, and it offers us a direction to improve the catalytic efficiency of this reaction.

\section{Conclusions}

In this work, low-cost and porous natural diatomite can be effectively introduced as a catalyst support by simple pretreatment for direct synthesis of DMC from carbon dioxide and methanol. The $2 \mathrm{Cu}-\mathrm{Ni}$ /diatomite catalysts prove highly active for direct synthesis of DMC, and 15\% (2Cu$\mathrm{Ni}$ /diatomite gives the highest methanol conversion of 4.50 with DMC selectivity of $91.2 \%$ together with more than 6-hour lifetime $\left(120^{\circ} \mathrm{C}, 1.2 \mathrm{MPa}\right)$. From the results of experiments, the bimetallic nanoparticles are well dispersed and presumably alloyed under the preparation conditions. The existence of electron-rich and electron-deficient centers resulted from the strong interaction of diatomite with $\mathrm{Cu}-$ $\mathrm{Ni}$, and the synergy of $\mathrm{Cu}-\mathrm{Ni}$ alloy may be responsible for the high activity of this catalyst. This work can facilitate us to better understand the mechanism of this reaction and speed the scientific progress of peers in direct synthesis of DMC.

\section{Acknowledgments}

The authors would like to thank the China High-Tech Development 863 Program (2009AA034900, 2009AA03Z340), the Guangdong Province Universities and Colleges Pearl River Scholar Funded Scheme (2010), the Guangdong Province Sci \& Tech Bureau (Key Strategic Project Grant no. 2008A080800024, 10151027501000096), and the Guangdong Education Bureau (Key Project. cxzd1004), the Chinese Universities Basic Research Founding for financial support of this work.

\section{References}

[1] M. Aresta and E. Quaranta, "Carbon dioxide: a substitute for phosgene," CHEMTECH, vol. 27, no. 3, pp. 32-40, 1997.

[2] A. A. G. Shaikh and S. Sivaram, "Organic carbonates," Chemical Reviews, vol. 96, no. 3, pp. 951-976, 1996.

[3] P. Tundo, G. Moraglio, and F. Trotta, "Gas-liquid phasetransfer catalysis: a new continuous-flow method in organic synthesis," Industrials and Engineering Chemistry Research, vol. 28, no. 7, pp. 881-890, 1989.

[4] Y. Ono, "Catalysis in the production and reactions of dimethyl carbonate, an environmentally benign building block," Applied Catalysis A, vol. 155, no. 2, pp. 133-166, 1997.

[5] P. G. Jessop, T. Ikariya, and R. Noyori, "Homogeneous catalysis in supercritical fluids," Chemical Reviews, vol. 99, no. 2-3, pp. 475-493, 1999.
[6] M. S. Han, B. G. Lee, B. S. Ahn, K. Y. Park, and S. I. Hong, "Kinetics of dimethyl carbonate synthesis from ethylene carbonate and methanol using alkali-metal compounds as catalysts," Reaction Kinetics and Catalysis Letters, vol. 73, no. 1, pp. 33-38, 2001.

[7] T. Tatsumi, Y. Watanabe, and K. A. Koyano, "Synthesis of dimethyl carbonate from ethylene carbonate and methanol using TS-1 as solid base catalyst," Chemical Communications, no. 19 , pp. 2281-2282, 1996.

[8] M. Wang, N. Zhao, W. Wei, and Y. Sun, "Synthesis of dimethyl carbonate from urea and methanol over $\mathrm{ZnO}$," Industrial and Engineering Chemistry Research, vol. 44, no. 19, pp. 7596-7599, 2005.

[9] J. Puga, M. E. Jones, D. C. Molzahn, and G. E. Hartwell, "Production of dialkyl carbonates using copper catalysts," U.S. Patent 5387708, 1995.

[10] K. M. Yu, I. Curcic, J. Gabriel, and S. C. Tsang, "Recent advances in CO2 capture and utilization," ChemSusChem, vol. 1, no. 11, pp. 893-899, 2008.

[11] J. C. Choi, K. Kohno, Y. Ohshima, H. Yasuda, and T. Sakakura, "Tin- or titanium-catalyzed dimethyl carbonate synthesis from carbon dioxide and methanol: large promotion by a small amount of triflate salts," Catalysis Communications, vol. 9, no. 7, pp. 1630-1633, 2008.

[12] Q. Cai, C. Jin, B. Lu, H. Tangbo, and Y. Shan, "Synthesis of dimethyl carbonate from methanol and carbon dioxide using potassium methoxide as catalyst under mild conditions," Catalysis Letters, vol. 103, no. 3-4, pp. 225-228, 2005.

[13] K. Tomishige, T. Sakaihori, Y. Ikeda, and K. Fujimoto, "A novel method of direct synthesis of dimethyl carbonate from methanol and carbon dioxide catalyzed by zirconia," Catalysis Letters, vol. 58, no. 4, pp. 225-229, 1999.

[14] K. W. La and I. K. Song, "Direct synthesis of dimethyl carbonate from $\mathrm{CH} 3 \mathrm{OH}$ and $\mathrm{CO} 2$ by H3PW12O40/CexTi1xO2 catalyst," Reaction Kinetics and Catalysis Letters, vol. 89, no. 2, pp. 303-309, 2006.

[15] Z. F. Zhang, Z. T. Liu, Z. W. Liu, and J. Lu, "DMC formation over Ce $0.5 \mathrm{Zr} 0.5 \mathrm{O} 2$ prepared by complex-decomposition method," Catalysis Letters, vol. 129, no. 3-4, pp. 428-436, 2009.

[16] X. L. Wu, M. Xiao, Y. Z. Meng, and Y. X. Lu, "Direct synthesis of dimethyl carbonate on H3PO4 modified V2O5," Journal of Molecular Catalysis A, vol. 238, no. 1-2, pp. 158-162, 2005.

[17] S. Zhong, H. Li, J. Wang, and X. Xiao, "Study on Cu-Ni/ZrO2$\mathrm{SiO} 2$ catalyst for direct synthesis of DMC from $\mathrm{CO} 2$ and CH3OH," Chinese Journal of Catalysis, vol. 21, no. 2, pp. 117120, 2000.

[18] X. L. Wu, Y. Z. Meng, M. Xiao, and Y. X. Lu, "Direct synthesis of dimethyl carbonate (DMC) using $\mathrm{Cu}-\mathrm{Ni} / \mathrm{VSO}$ as catalyst," Journal of Molecular Catalysis A, vol. 249, pp. 93-97, 2006.

[19] X. J. Wang, M. Xiao, S. J. Wang, Y. X. Lu, and Y. Z. Meng, "Direct synthesis of dimethyl carbonate (DMC) from methanol and carbon dioxide under pressure and UV irradiation," Research Journal of Chemistry and Environment, vol. 12, no. 2, pp. 22-26, 2008.

[20] X. J. Wang, M. Xiao, S. J. Wang, Y. X. Lu, and Y. Z. Meng, "Direct synthesis of dimethyl carbonate from carbon dioxide and methanol using supported copper $(\mathrm{Ni}, \mathrm{V}, \mathrm{O})$ catalyst with photo-assistance," Journal of Molecular Catalysis A, vol. 278, no. 1-2, pp. 92-96, 2007.

[21] J. Bian, M. Xiao, S. Wang, X. Wang, Y. Lu, and Y. Meng, "Highly effective synthesis of dimethyl carbonate from methanol and carbon dioxide using a novel copper-nickel/ graphite bimetallic nanocomposite catalyst," Chemical Engineering Journal, vol. 147, no. 2-3, pp. 287-296, 2009. 
[22] J. Bian, M. Xiao, S. Wang, Y. Lu, and Y. Meng, "Direct synthesis of DMC from $\mathrm{CH} 3 \mathrm{OH}$ and $\mathrm{CO} 2$ over $\mathrm{V}$-doped $\mathrm{Cu}-\mathrm{Ni} / \mathrm{AC}$ catalysts," Catalysis Communications, vol. 10, no. 8, pp. 1142$1145,2009$.

[23] D. J. Zhou, D. Q. Zhou, X. H. Cui, F. M. Wang, M. Y. Huang, and Y. Y. Jiang, "Hydrogenation of aldehydes catalyzed by kieselguhr-supported carboxymethylcellulose-nickel complex," Polymers for Advanced Technologies, vol. 15, no. 4, pp. 218-220, 2004.

[24] C. S. Yao and H. S. Weng, "Liquid-phase oxidation of cyclohexanone to dibasic acids over supported cerium catalysts," Chemical Engineering Science, vol. 47, no. 9-11, pp. 27452750, 1992.

[25] S. Bessell, "Support effects in cobalt-based fischer-tropsch catalysis," Applied Catalysis A, vol. 96, no. 2, pp. 253-268, 1993.

[26] K. Ogura, M. Kawano, and D. Adachi, "Dark catalytic reduction of $\mathrm{CO} 2$ over photo-pretreated $\mathrm{NiO} / \mathrm{ksgr}$ catalyst," Journal of Molecular Catalysis, vol. 72, no. 2, pp. 173-179, 1992.

[27] M. D. Cangiano, A. C. Carreras, M. W. Ojeda, and M. D. Ruiz, "A new chemical route to synthesize $\mathrm{Cu}-\mathrm{Ni}$ alloy nanostructured particles," Journal of Alloys and Compounds, vol. 458, no. 1-2, pp. 405-409, 2008.

[28] K. W. La, J. C. Jung, H. Kim, S. H. Baeck, and I. K. Song, "Effect of acid-base properties of H3PW12O40/CexTi1-xO2 catalysts on the direct synthesis of dimethyl carbonate from methanol and carbon dioxide: aTPD study of H3PW12O40/CexTi1-xO2 catalysts," Journal of Molecular Catalysis A, vol. 269, no. 1-2, pp. 41-45, 2007. 

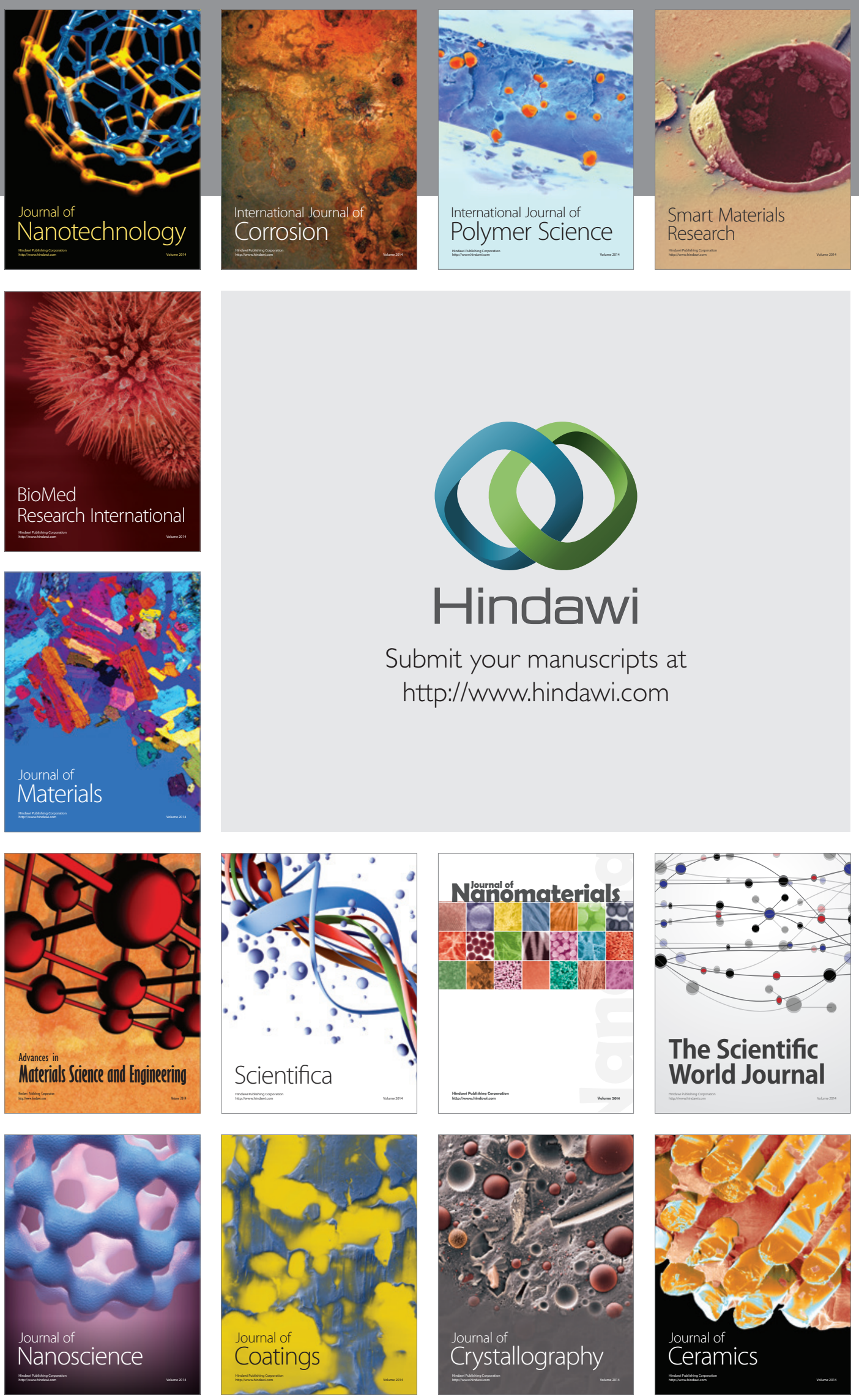

The Scientific World Journal

Submit your manuscripts at

http://www.hindawi.com

\section{World Journal}

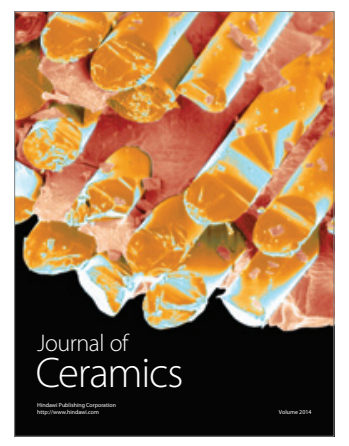

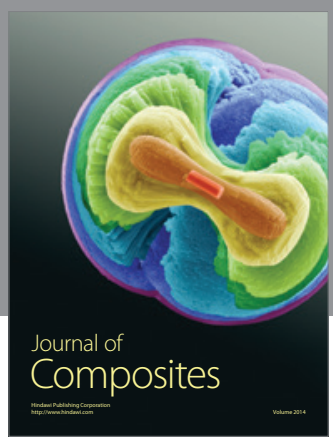
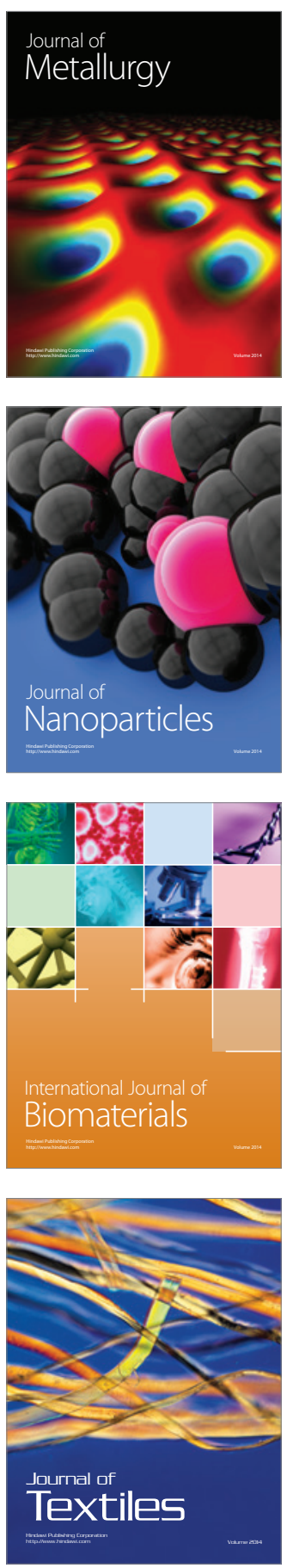